\title{
The search for postglacial rebound near the Lambert Glacier, Antarctica
}

\author{
Paul Tregoning, Andrew Welsh, Herbert McQueen, and Kurt Lambeck \\ Research School of Earth Sciences, The Australian National University, Canberra, ACT 0200, Australia
}

(Received January 17, 2000; Revised June 22, 2000; Accepted June 22, 2000)

\begin{abstract}
A GPS network has been installed to monitor vertical crustal movement in the Lambert Glacier region, East Antarctica. The program commenced in January 1998 with a solar-powered GPS system installed at Beaver Lake. Solar-powered observations were also made late in the Antarctic summer of 1999. In January 2000, two new solarpowered sites will be installed to expand the monitoring network. In addition, we will be installing a hydrogen fuel cell power system at Beaver Lake to enable the equipment to operate throughout the winter months when solar power is not available. In this paper we outline the equipment which has been developed in order to operate remote GPS equipment in Antarctica, provide predictions of the expected rate of rebound and comment on preliminary results from the data collected to date.
\end{abstract}

\section{Introduction}

Changes in the ice load in Antarctica since the Last Glacial Maximum (LGM) cause present-day changes in vertical motion on the continent because of the viscously-delayed rebound of the crust. Observations of sea-level changes along the Antarctic coast will therefore contain both isostatic and eustatic signatures. Separation of the two components requires measurements of relative sea-level change using tide gauges and of the crustal rebound. Perhaps more importantly, the rebound component contains information on past ice volumes over Antarctica.

Several indirect lines of evidence suggest that the Antarctic ice volume has been substantially larger in the past. This includes geological estimates of crustal rebound in the Vestfold Hills near Davis (Zwartz et al., 1997, 1998); age-height relationships of marginal moraines elevated above the present ice surface in the Lambert Glacier (Stone et al., 1998) and global considerations of ice-ocean mass balance (Nakada and Lambeck, 1988; Yokoyama et al., 2000). However, debate remains about the amount of ice reduction that has occurred since the time of the LGM (c.f. for example, the estimates by Denton and Hughes (1981) and Huybrechts (1990)). Debate also remains about the recent and present mass balance of Antarctica. Some indirect indicators suggest that the reduction in the Antarctic ice sheet continued up to the present (as for the ice sheet model calculations of Huybrechts (1990) or the Late Holocene sea-level inferences of Fleming et al. (1998)) but direct measurements remain few and uncertain.

By combining rates of vertical movement derived from GPS observations with geological and glaciological indicators of rebound and ice movements, it becomes possible to separate some of the factors contributing to the sea level signals, isostatic rebound and ice-ocean balance issues. The Lambert Glacier represents one of the largest drainage basins

Copy right $(\mathrm{C})$ The Society of Geomagnetism and Earth, Planetary and Space Science (SGEPSS); The Seismological Society of Japan; The Volcanological Society of Japan; The Geodetic Society of Japan; The Japanese Society for Planetary Sciences. of East Antarctica and is a particularly appropriate study area because substantial fluctuations in glacier volume may have occurred there (e.g. Stone et al. (1998)). Other geological and glaciological studies have been conducted there and, because of the existence of outcropping rock surfaces, a GPS transect can be established well into the ice sheet interior.

It has been shown that GPS can be used to detect postglacial rebound (Scherneck et al., 1998). However, detection of these vertical motions requires long-period observations with high frequency sampling at permanent stations. Tregoning et al. (1999) have shown that remote GPS sites can be operated successfully during the summer seasons using the available solar power. Additional information on similar projects in the Trans-Antarctic Mountains and Marie Byrd Land is available at http: //geodynamics . jpl . nasa . gov/antarctica. The major difficulty of conducting GPS observations in remote locations in Antarctica is providing power during winter months when there is insufficient solar power available to run the equipment.

We have installed a network of GPS sites in the Lambert Glacier region (Fig. 1) to establish whether postglacial rebound is significant there. A solar-powered site has been operating at Beaver Lake since January 1998 and in January 2000 we will be installing a further two solar-powered sites-one at the coast (Landing Bluff) and one $\sim 450 \mathrm{~km}$ inland (Dalton Corner). In addition, we will be installing a hydrogen fuel cell at the Beaver Lake site in order to provide power throughout the winter period when solar power is not available.

In this paper, we review the predicted rates of uplift in the region, describe the existing solar-powered systems and the new power management system to be installed in January 2000 and present preliminary results from the data recorded to date.

\section{Predicted Uplift}

Zwartz et al. (1999) computed predictions of glacioisostatic uplift rates along a transect across the Lambert 


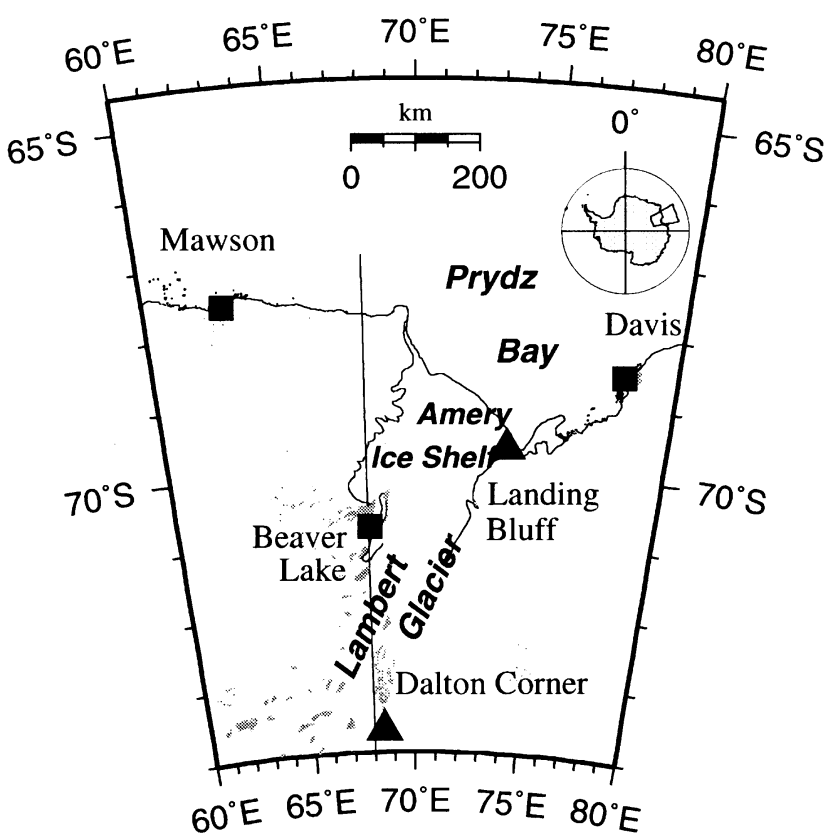

Fig. 1. Location of GPS sites in the Lambert Glacier region, Antarctica. Established GPS sites (squares) and sites to be installed in 2000 (triangles) are plotted. The receivers at Mawson and Davis are operated by the Australian Surveying and Land Information Group and form part of the Australian Regional Geodetic Network. Transect line along which uplift predictions have been made is shown.

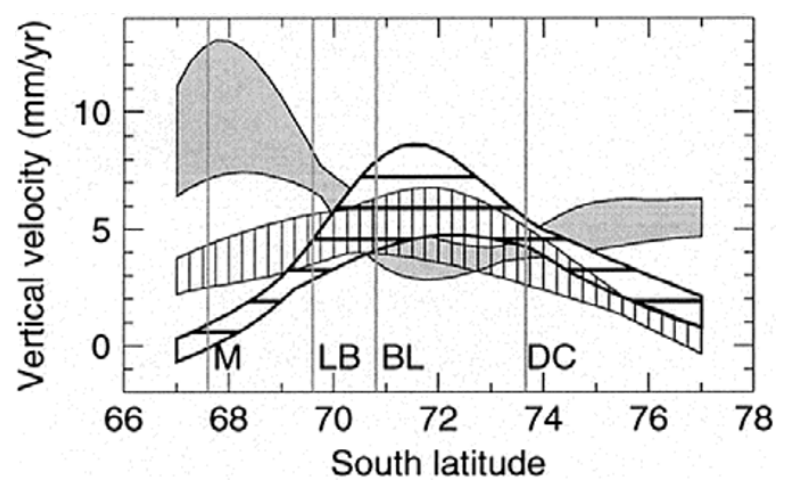

Fig. 2. Predicted rates of uplift along a transect through the Lambert Glacier. Vertical hatching: ANT3 model; horizontal hatching: HUY model; shaded: ICE-3G model. The approximate locations of the GPS sites are indicated. M: Mawson; BL: Beaver Lake; LB: Landing Bluff; DC: Dalton Corner. The shading for each ice model indicates the range of predictions for different plausible Earth model parameters. Sites have been projected onto the transect along which uplift predictions have been made. Adapted from Zwartz et al. (1999).

Glacier from the coast to the southernmost rock outcrops, about $700 \mathrm{~km}$ inland. Such predictions are more strongly dependent on the choice of ice models than on Earth models (see Zwartz et al. (1999) for details of parameters used) as can be seen in Fig. 2 for three different models of the changes in Antarctic ice during the last glacial cycle. The three models-ANT3 (Nakada and Lambeck, 1988), ICE3G (Tushingham and Peltier, 1991) and HUY (Huybrechts, 1990) - are based on different assumptions and approaches. The important feature here is that they lead to quite different

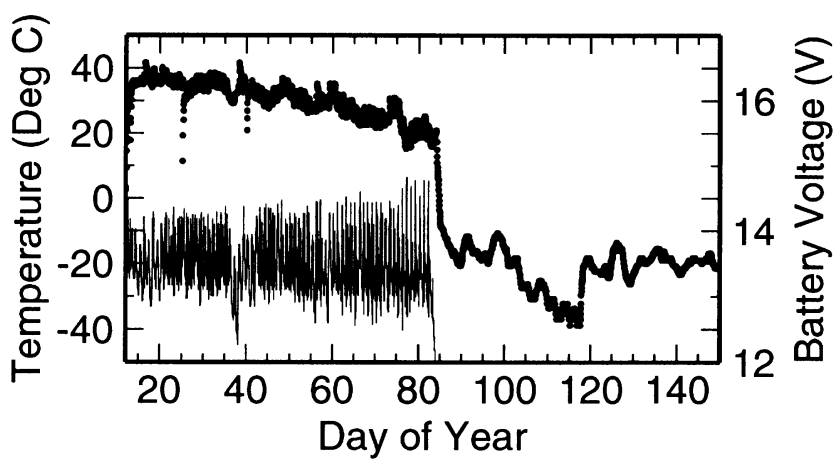

Fig. 3. Internal housing temperature (circles) and battery voltage (thin line) for the 1998 solar-powered GPS equipment. The equipment ceased operating on day 084 because of a lack of power. The internal temperature rapidly cooled then tracked the external air temperature. Temperature drops on days 25 and 40 were caused by the opening of the suitcase in order retrieve GPS data from the computer.

rebound predictions such that observations of this rebound may help discriminate between models. For example, a relative change in height of $+5 \mathrm{~mm} / \mathrm{yr}$ between Mawson and Beaver Lake would agree with the HUY model but would not be compatible with the ICE-3G or ANT-3 models.

\section{Solar-Powered Systems}

In January 1998, a simple solar-powered GPS system was installed at Beaver Lake as a pilot phase of the main project. The system comprised $4 \times 53 \mathrm{~W}$ solar panels, two $28 \mathrm{Ah}$ gelcell batteries, a laptop computer, Ashtech Z-XII GPS receiver and a small datalogger for recording system temperatures and voltages (Tregoning et al., 1999). The system operated from 12 January until 25 March at which time there was insufficient solar power available to maintain operation. A total of 70 days of GPS data were recovered, along with diagnostic data which showed that the temperature maintained inside the insulated suitcase was typically above $30^{\circ} \mathrm{C}$. Battery voltages never fell below $12 \mathrm{~V}$ until the system actually failed in late March (Fig. 3).

The GPS antenna was mounted on a plate connected to bedrock via a central rod (driven $200 \mathrm{~mm}$ into the rock) and three supporting rods drilled into the rock (150 $\mathrm{mm}$ deep) (Fig. 4). The pre-amp base of the antenna sits $\sim 50 \mathrm{~mm}$ above the ground. While the close proximity of the ground will affect the electrical properties of the antenna, it was thought that this type of mark provided a stable, long-lasting monument that was quick to install and required very few materials to construct. The mark was designed by the Geodesy Section of the Australian Surveying and Land Information Group and took less than 1 hour to install.

It was not known whether the original system would survive the Antarctic winter. When revisited in January 1999, the system was found to be intact with no apparent damage to any of the solar panels, frame or GPS antenna. All electronic equipment functioned normally once warmed up; however, the batteries were no longer capable of holding charge or supplying power. We do not have a record of the external air temperature while the equipment was operating; however, the temperature dropped to at least $-40^{\circ} \mathrm{C}$ in April 1998 (Fig. 3). Without knowing that the first system had survived, 


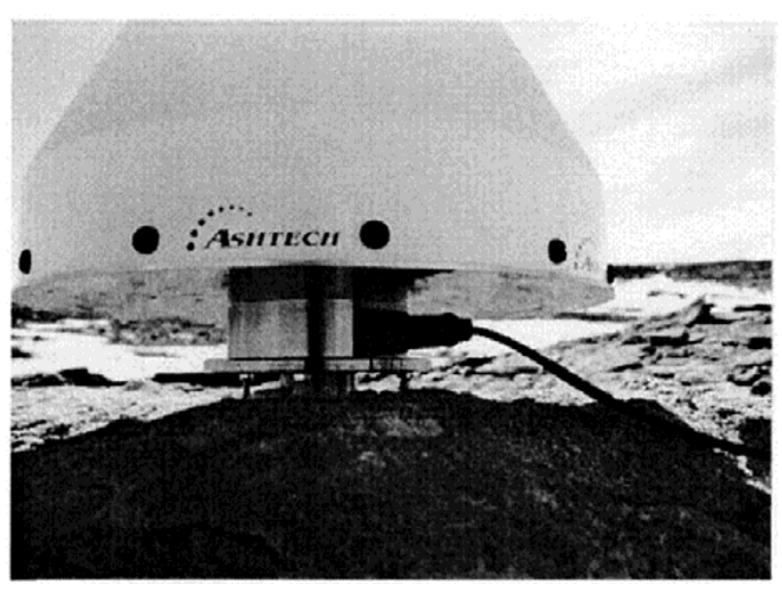

Fig. 4. Closeup of the GPS antenna mounting.

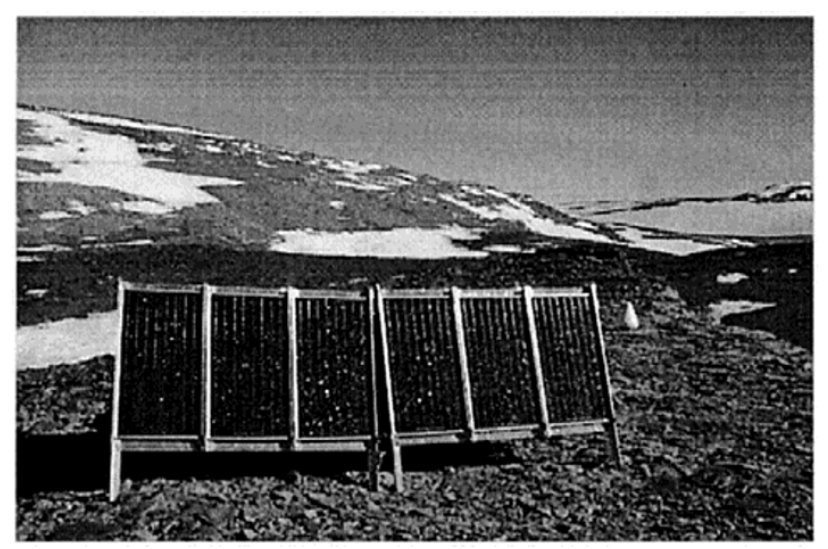

Fig. 5. Setup of the equipment at Beaver Lake in 1999. The GPS receiver and batteries are in a plastic suitcase behind the solar panels, while the GPS antenna and radome can be seen on the ground behind and to the right of the panels.

we designed a more rugged system, increasing the number of solar panels from 4 to 6 and increasing the battery capacity to $3 \times 73$ Ah gellcell batteries (Fig. 5). This system was left operating and will be revisited in January 2000 when the data recorded since 2 February 1999 will be recovered.

It is possible that the GPS antenna and radome may become covered with snow. All visits to the Beaver Lake site have been in mid-summer and no one has ever visited the site during or immediately after a blizzard or snowfall to know how much snow accumulates at the site. However, at the time of the visits in the past three years the ground was snow-free even though snow had accumulated in surrounding areas (see Fig. 5) The site is windy and the antenna has been placed to minimize snow accumulation (Tregoning et al., 1999).

\section{Equipment for Deployment in 2000}

In January 2000 we will be installing integrated power systems designed to operate throughout the Antarctic winter. Power will be supplied from a combination of solar and power generated by a hydrogen Proton-Exchange-Membrane (PEM) fuel cell. The fuel cell is a 22 cell PEM stack with no moving parts and generates electricity along with byprod- ucts of water and heat; hence, it is an environmentally clean power supply which will not adversely affect the Antarctic environment.

The fuel cell will be running at all times; however, it will only be consuming significant quantities of hydrogen when a load is connected to it, that is, when it is required to recharge the batteries. We power the $22 \mathrm{~W}$ parasitic loads of the fuel cell (fans and air pumps) from the batteries, thereby reducing the amount of hydrogen consumed in the summer months when solar power can be used to maintain the battery charge.

We have developed a low-powered controller (PCON, $<0.8 \mathrm{~W}$ ) which continuously monitors the operation of the system and makes decisions about the power and heating needs of the equipment. If the battery voltages reach critically low levels the PCON will check whether the solar panels are capable of recharging the batteries. If not, it will connect the fuel cell to the batteries in order to maintain the power supply for the GPS receiver. The fuel cell will provide $\sim 3$ Amperes to slowly recharge the batteries. At all times, the batteries will be supplying power to the GPS receiver, the PCON itself and the parasitic loads for the fuel cell. There is an absolute minimum voltage level set at which point the PCON will connect the fuel cell, irrespective of the availability of solar power, in order to prevent a total power failure of the system.

Every 20 minutes, the PCON reads and records temperature and voltage sensors and the status of the heaters and batteries. It also communicates with the fuel cell controller to receive diagnostic data on temperatures and voltages within the fuel cell stack. These data are transferred to the computer once per day (see below). In addition to monitoring battery voltages, the PCON measures and records the temperature at three locations within the equipment housing as well as the external air temperature and pressure. If the internal temperature falls below $9^{\circ} \mathrm{C}$, the PCON will begin turning on up to three $14 \mathrm{~W}$ heaters to increase the temperature of the box.

Also included in the system are a low-powered (2.3 W) PC104 card computer with $440 \mathrm{Mb}$ solid-state disk, a Saturn-B satellite phone (capable of transmitting data back to Australia at $9600 \mathrm{bits} / \mathrm{second}$ ) and an Ashtech Z-XII GPS receiver. The computer $(2.3 \mathrm{~W})$ and satellite phone $(28 \mathrm{~W}$ standby, $110 \mathrm{~W}$ transmit) will only be powered up when required while the GPS receiver $(12.5 \mathrm{~W})$ will operate continuously.

The equipment has been housed in an alumimium-clad wooden box lined with Styrofoam. If the equipment is to operate throughout the year, the thermal design of the insulation must be capable of adapting to outside air temperatures ranging from $-45^{\circ} \mathrm{C}$ to $-5^{\circ} \mathrm{C}$ and internal equipment power ratings from 15 to $45 \mathrm{~W}$. Since the fuel cell should only be required for power generation during the cold periods of the year, the additional heat generated during this time will compensate for the lower external temperatures, although it is possible to have comparatively mild temperatures (e.g. $-10^{\circ} \mathrm{C}$ ) in winter during blizzards. By using an appropriate thickness of insulation we have designed a passive insulation system (with no moving parts) in which the internal temperature will always remain within acceptable levels $(+5$ to $+50^{\circ} \mathrm{C}$ ) depsite variations in the outside temperature and the amount of heat generated inside the housing by the operating equipment. 
We will be installing one of these systems at Beaver Lake in January 2000. Because the fuel cells have not been proven to work in the Antarctic environment we will be installing a similar system at Davis so that the fuel cell can be visually inspected during the year. In particular, we will monitor the performance of the exhaust pipe and heater to see whether we are able to prevent freezing of the exhaust water vapour. In the event that we lose satellite communication with the system at Beaver Lake, we will still receive feedback from the system at Davis which can be manually downloaded and inspected. In this manner we will field test our electronics system and validate the operation of the fuel cell and our insulated housing.

\section{Results}

The data obtained from the 1998 and 1999 seasons have been analysed using the GAMIT/GLOBK software (King and Bock, 1999; Herring, 1999) following the procedures of, for example (Dong et al., 1998). The methodology is quite standard and will not be discussed in detail here; essentially, the local GPS data are combined with other data from up to 80 global IGS stations to compute a free-network polyhedron of sites which is then aligned with the ITRF97. We are computing our own global solutions of the GPS data to ensure that all the analyses are performed with consistent orbital modelling, elevation cutoff angles and data weighting. The gaps in our time series (Fig. 6) indicate data which we have not yet analysed, although more complete time series are available at, for example, http://sideshow.jpl.nasa.gov/mbh/ series.html and http://www-gpsg.mit.edu/ $\sim$ fresh/index.html.

At this stage, we have only retrieved data from the Beaver Lake site from early 1998 (days of year 012-084) and a small amount of data from 1999 (days-of-year 021-034). From these data, we could estimate a horizontal and vertical velocity for the site; however, the span of data is too short to allow an accurate estimate of velocities to be made. The short term scatter of the daily solutions is $\sim 7 \mathrm{~mm}$. We acknowledge that there are long-period, systematic errors remaining in the GPS time series which are currently likely to prevent accurate uplift rates from being estimated.

Figure 6 shows the daily estimates which are currently calculated for DAV1, MAW1 and BVLK. Comprehensive geodetic time series of site coordinates show temporal variations in height of up to $\pm 15 \mathrm{~mm}$. This is not peculiar to the Antarctic region; rather, it is seen at most sites throughout the world by most analysis groups (including IGS Analysis Centers). There is usually coherence between the unmodelled signals for sites in close proximity (that is, within $\sim 1000 \mathrm{~km}$ ). Here, we do not wish to state an estimate of the postglacial rebound occurring at Mawson and Beaver Lake because we do not believe that we have sufficient data nor sufficiently accurate analysis of the data to be able to make a reliable estimate. Data will continue to be collected at these and other sites in the region and investigations are underway (by the authors and many other international geodetic analysis groups) into the possible causes of the long-period, systematic errors which remain in the GPS time series.

Such unmodelled systematic trends in the data are only evident in long time series of height estimates with high sam-
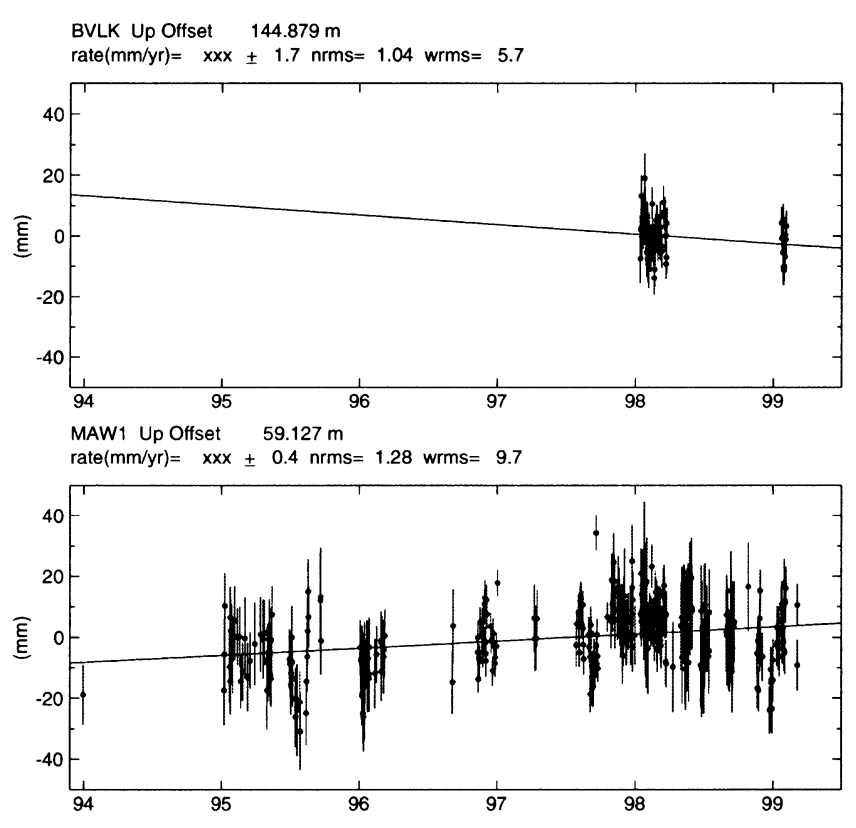

DAV1 Up Offset $44.431 \mathrm{~m}$

$\operatorname{rate}(\mathrm{mm} / \mathrm{yr})=\quad x x x \pm 0.4 \mathrm{nrms}=1.32 \mathrm{wrms}=10.8$

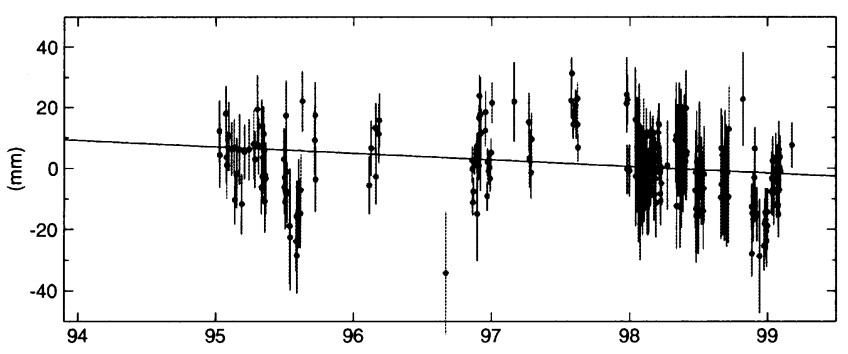

Fig. 6. Daily height estimates at Beaver Lake, Mawson and Davis. Note the long-period variation in height at MAW1 and DAV1 sites, indicative of significant unmodelled signal. We do not believe that the estimated velocities are reliable at this stage and have deliberately refrained from quoting an uplift rate.

pling frequencies. It is for this reason that studies aiming to estimate rates of postglacial rebound need to be conducted over several years with continuous observations at permanent sites. When such irregularities in our height estimates are understood and can be removed we will be able to estimate accurate uplift rates.

Between the submission and revision of this paper the equipment as described above was installed at Beaver Lake and Davis along with the two new solar-powered sites at Landing Bluff and Dalton Corner. An additional 23 days of GPS data observed in 1999 were recovered from Beaver Lake and data collected there in 2000 was successfully transmitted to Australia for several days via the satellite phone before a software problem on the remote computer prevented further interrogation of the remote system. The fuel cell at Beaver Lake was left operating; however, because we cannot contact the system we do not know how well it is performing. The fuel cell at Davis was removed at the end of the summer season and will be replaced with an improved design in the coming season. The electronics are still operating at Davis although we have manually disconnected all power loads except the power controller itself in an attempt to conserve stored battery power until solar charging of the batteries be- 
comes possible with the return of the sun in July/August. System diagnostic data recovered by personnel at Davis can be viewed at http: //rses. anu . edu.au/geodynamics / and indicate that the equipment and insulation are functioning as expected.

Acknowledgments. We are grateful to many people for installing and downloading equipment on our behalf, in particular to Bob Twilley (AUSLIG-January 1998), Matt King (University of Tasmania-January 1999) and Kevin Fleming (RSES-January 2000). We thank Frederick Jobin for servicing and downloading the system at Davis during 2000, personnel at the Australian Antarctic Division (including Station Leaders, Field Training Officers and many expeditioners) for support over several years, Geoff Dannock (Australian Antarctic Division) for organising logistical support for this program, AUSLIG for making available the GPS data at Mawson and Davis and the IGS for the global tracking data. The fuel cells were supplied by Hydrogenics Corporation, Canada. Reviews by Carol Raymond and an anonymous reviewer helped improve this manuscript.

\section{References}

Denton, G. H. and T. J. Hughes, The last great ice sheets, John Wiley and Sons, p. 484, 1981.

Dong, D., T. A. Herring, and R. W. King, Estimating regional deformation from a combination of space and terrestrial geodetic data, J. Geod., 72, 200-214, 1998.

Fleming, K., P. Johnston, D. Zwartz, Y. Yokoyama, K. Lambeck, and J. Chappell, Refining the eustatic sea-level curve since the Last Glacial Maximum using far and intermediate-field sites, Earth Planet. Sci. Lett., 163, 327-342, 1998.

Herring, T. A., GLOBK global Kalman filter VLBI and GPS analysis program, version 4.1, Mass. Inst. of Technol., Cambridge Mass, 1999.

Huybrechts, P., The Antarctic ice sheet during the last glacial-interglacial cycle: a three-dimensional experiment, Annals Glaciology, 14, 115-119, 1990.
King, R. W. and Y. Bock, Documentation for the GAMIT GPS analysis software release 9.92, Mass. Inst. of Technol., Cambridge Mass, 1999.

Nakada, M. and K. Lambeck, The melting history of the late Pleistocene Antarctic ice sheet, Nature, 333, 36-40, 1988.

Scherneck, H.-G., J. M. Johansson, J. X. Mitrovica, and J. L. Davis, The BIFROST project: GPS determined 3-D displacement rates in Fennoscandia from 800 days of continuous remote GPS observations in the SWEPOS network, Tectonophys., 294, 305-321, 1998.

Stone, J. O., D. Zwartz, M. C. G. Mabin, K. Lambeck, D. Fabel, and L. K. Fifeld, Exposure dating constraints on ice volume and retreat history in East Antarctica, and prospects in West Antarctica, in Chapman Conference on West Antarctic Ice Sheet, edited by R. Bindschadler and H. Borns, Sept 13-18, University of Maine, Orono, Maine (abstract) p. 109, 1998.

Tregoning, P., B. Twilley, M. Hendy, and D. Zwartz, Monitoring isostatic rebound in Antarctica with the use of continuous remote GPS observations, GPS Solutions, 2, 70-75, 1999.

Tushingham, A. M. and W. R. Peltier, ICE-3G: A new global model of late Pleistocene deglaciation based upon geophysical predictions of postglacial relative sea level change, J. Geophys. Res., 96, 4497-4523, 1991.

Yokoyama, Y., K. Lambeck, P. De Deckker, P. Johnston, and L. K. Fifeld, Timing of the Last Glacial Maximum from observed sea-level minima, Nature, 406, 713-716, 2000.

Zwartz, D., K. Lambeck, M. Bird, and J. Stone, Constraints on the former Antarctic ice sheet from sea-level observations and geodynamic modelling, in The Antarctic Region: Geological Evolution and Processes, edited by C. Ricci, pp. 821-828, Terra Antarctica Publication, Siena, 1997.

Zwartz, D., M. Bird, J. Stone, and K. Lambeck, Holocene sea-level change and ice-sheet history in the Vestfold Hills, East Antarctica, Earth Planet. Sci. Lett., 155, 131-145, 1998.

Zwartz, D., P. Tregoning, K. Lambeck, P. Johnston, and J. Stone, Estimates of present-day glacial rebound in the Lambert Glacier region, Antarctica, Geophys. Res. Lett., 26, 1461-1464, 1999.

P. Tregoning (e-mail: pault@rses.anu.edu.au), A. Welsh, H. McQueen, and K. Lambeck 